(C) 2021. This manuscript version is made available under the CC-BY-NC-ND 4.0 license http://creativecommons.org/licenses/by-nc-nd/4.0/

\title{
An Evaluation of Inkjet Printed Amino Acid Fingerprint Test Targets for Ninhydrin Process Monitoring - and some Observations
}

Ruth Croxton ${ }^{\mathrm{a}, \mathrm{b}}$, Terry Kent ${ }^{\mathrm{c}}$, Anthony Littlewood ${ }^{\mathrm{a}}$, Millicent Smith ${ }^{\mathrm{a}}$

aSchool of Chemistry, University of Lincoln, Brayford Pool, Lincoln, LN6 7TS

${ }^{b}$ Department of Biomedical Sciences, University of Hull, Cottingham Road, Hull, HU6 7RX (present address)

${ }^{\mathrm{c} I n d e p e n d e n t ~ R e s e a r c h e r ~}$

\section{Acknowledgements}

The authors would like to thank Bounded Solutions Ltd. for supplying prototype test targets in a number of revised designs and subsequently scanning processed targets. They would also like to express their appreciation to the laboratory support staff, students and other willing donors without which such trials would be impossible.

\section{Declarations of interest: none}

\section{Corresponding author}

Dr. Ruth Croxton

Postal address: Department of Biomedical Sciences, University of Hull, Cottingham Road, Hull, HU6 7RX

Email address: r.croxton@hull.ac.uk 


\section{Highlights}

- Substantial variations worldwide detected in operational ninhydrin process

- Inkjet-printed amino acid on paper emulates fingermarks for ninhydrin evaluation

- Quality assurance for operational ninhydrin fingermark treatment 


\title{
An Evaluation of Inkjet Printed Amino Acid Fingerprint Test Targets for Ninhydrin Process Monitoring - and Some Observations
}

\begin{abstract}
Ninhydrin was implemented as the primary police method of developing latent fingermarks on paper, cardboard and some other porous surfaces from the late 1960s. Some researchers have used individual amino acids, or mixtures of amino acids, as a method of testing the effectiveness of reagent formulations. It was not however known whether simple mixtures of amino acids could effectively emulate latent fingermarks in reactions with reagents such as ninhydrin.
\end{abstract}

The first parts of this study compared the effects of ninhydrin fingermark treatments used internationally in various police laboratories on test targets created by inkjet printing graduated concentrations of a representative mixture of amino acids in a series of blocks on paper. Variations in intensity of development were observed between laboratories which used various formulations and heat and humidity post treatment protocols. In a further trial in 2015 several participants in the International Fingerprint Research Group (IFRG) meeting processed test targets in their own laboratories and submitted them for measurement. Again, significant variation in developed intensity was observed.

The depletion of the activity of ninhydrin solutions during use was investigated in early evaluations of the test targets. An established fingerprint laboratory then processed a number of samples from a batch of targets to examine batch consistency.

This was followed by designing a new test target which enabled comparisons between the developed intensity of printed test target blocks alongside depletion series of split, natural donor fingermarks. A panel of 20 donors provided depletion fingermarks and four ninhydrin formulations and treatment protocols were used. The developed test target blocks were scanned, intensity of development measured, and the results compared with the fingermark development which was evaluated by three assessors using two types of scale.

Good correlation between the intensity of the developed test targets and latent fingermark quality and intensity scores was observed with the four ninhydrin treatment protocols, including some which used deliberately downgraded ninhydrin concentrations. This type of evaluation was carried out a second time to investigate modified heat and humidity protocols.

The use of such test targets for routine reagent quality control and process verification would appear to be far more accurate and reliable than the use of small numbers of donor fingermarks.

It is not clear why the different ninhydrin formulations investigated in the latter part of the work have very different optimum post treatment heating regimes. 


\section{KEYWORDS}

ninhydrin; inkjet-printing; amino acid; ISO/IEC 17025; accreditation; fingermark

\section{BACKGROUND}

\section{Optimisation of Ninhydrin as a Fingerprint Reagent}

Operationally there are many ninhydrin formulations and post treatment heat and humidity protocols now in use around the world in police and forensic laboratories. Since Oden $(1,2)$ reported the reaction of ninhydrin with the naturally occurring amino acids in latent fingermarks and its wide-scale implementation (3-7) a considerable body of research has been established. Many workers have sought to determine the reaction mechanism; specifically, the formation of Ruhemann's Purple (8-13). The need to change solvent systems due to flammability, environmental or cost and availability issues, has led to many laboratory studies and operational trials. Many of these trials (14-17) have used fingermark donors, pseudo-operational material or actual operational material. Some researchers however, including some earlier ones $(18,19)$, have used known concentrations of single or mixed amino acids, spotted usually onto paper, in an attempt to evaluate differences in the performance of various reagent formulations, or subsequent heat and humidity treatment protocols. It was however not known whether these amino acids would behave in the same way as those in the complex matrix of eccrine and sebaceous secretions present in most natural crime scene fingermarks. Analysis of latent fingermarks (20-28) has shown a wide variation in distribution and amounts of amino acids and all other components. This means that effective valid evaluation of enhancement techniques with latent fingermarks, including initial evaluation and optimisation of methods prior to implementation, requires large scale trials with significant numbers of donors (29-31). This is, however, not feasible for regular in-situ monitoring of the operational performance of the ninhydrin process.

\section{Implementation of ISO/IEC 17025 in Fingermark Development Laboratories}

The recent introduction of ISO/IEC 17025 into most areas of forensic science by many countries, and the need to formally validate and verify latent fingermark enhancement procedures, has raised the question of how this can most reliably and effectively be carried out.

\section{Process Verification}

Some fingermark enhancement laboratories process small numbers of 'test' fingermarks supplied by third parties as part of a verification procedure. However, as indicated above, the amino acid content of latent fingermarks is very variable, both within and between donors, and many latent fingermarks do not even develop visually with ninhydrin. Processing a small number of fingermarks of unknown quality is therefore inherently unreliable and cannot provide a quantitative assessment of reagent or laboratory performance. 


\section{Synthetic Fingermark Formulations}

Some suppliers of crime scene and fingerprinting materials market 'synthetic' sebaceous or eccrine material which can be deposited onto surfaces. The composition of most of these products is however unknown, or when known is unrepresentative of real fingermark composition. Storage lifetime and resulting chemical changes are also unknown. There is also no simple way of depositing representative and repeatable amounts of such material. The authors felt that these were unsuitable for realistic evaluation of reagents as reported by others $(32,33)$.

\section{Inkjet-Printed Amino Acid Targets}

Schwarz $(34,35)$ has demonstrated that aqueous solutions of a mixture of amino acids may be accurately inkjet-printed onto paper and used as test targets for amino acid reagents. This work was followed up by Jacobs $(36,37)$. The advantage of the method is primarily the ability to deposit controllable and repeatable amounts of amino acid mixtures onto most types of porous substrate. The aqueous solutions are however not chemically representative of the complex mixtures in latent fingermarks which consist usually of variable proportions of mixed sebaceous and eccrine sweat components.

Schwarz, Jacobs and others (38) have used printed grey scale blocks or reproduction fingermark targets with various surface concentrations to monitor the performance of ninhydrin and other amino acid reagents and in some cases used them in the optimisation of reagents.

The inkjet-printed test targets used for this series of trials were various versions under development and supplied by Bounded Solutions Ltd. who also scanned them.

\section{Effectiveness of Inkjet-Printed Amino Acid Targets as a Test Method}

Using such targets for process monitoring is only valid if the pure amino acid mixtures when deposited on paper react in a similar way to amino acids in typical latent fingermarks.

This relationship between the reaction of 'real' latent fingermarks and inkjet-printed deposits was studied in the latter phase of this programme of work. Establishing the relationship between the behaviour of mixed amino acid inkjet-printed test targets and a representative donor population of latent fingermarks was seen as a fundamental requirement to the adoption of such targets for operational laboratory validation and verification. This study is not an endorsement of any particular product, nor a methodology for preparing inkjet-printed amino acid targets. It is concerned with establishing whether the intensity (or optical density) of reaction products of a ninhydrin treatment with a representative mixture of amino acids, can be used to indicate, and monitor, the likely performance on operational crime scene exhibits. 


\section{METHODOLOGY}

\section{Programme Overview}

Phase I Various UK and European police laboratories participate in processing batch inkjet-printed targets with ninhydrin which were returned for scanning and comparison.

Phase II Inkjet-printed target batch consistency evaluation.

Phase III Investigation of ninhydrin solution depletion.

Phase IV Several international participants in IFRG 2015 meeting process and submit batch printed sample targets in their police laboratories for scanning and comparison. Further UK and European target processing and evaluation.

Phase V 20 donor comparative experiment investigating the relationship between developed target intensity and fingermark intensity/quality using new design of target.

Phase VI 20 donor comparative experiment investigating the effects of treatment protocols.

\section{Amino Acid Printed Target Design Development and Measurement - All Parts of Programme}

A Canon inkjet printer using refillable cartridges was used by Bounded Solutions Ltd. to print a series of blocks of stepped surface concentration of amino acids onto paper using an aqueous mixture which was a slightly modified formulation from that used by Schwarz (34).

During the course of this programme of work various designs of inkjet-printed target were developed by the supplier with different numbers of stepped amino acid concentration blocks in various configurations. It became apparent that 16 steps were providing more than adequate data of process performance. Some target designs were primarily for scanning such as Fig 1 but others such as Fig 2 were specifically to enable donated fingermarks to be split in half each with a set of reference test blocks of amino acid.

\section{Amino Acid Target Assessment}

A series of amino acid blocks of stepped concentration as in Fig 1 or 2 may be evaluated after processing with ninhydrin by simple visual examination looking for the faintest visible target block. This is open to observer subjectivity and a more reproducible and objective quantitative measure can be achieved by scanning the processed target and measuring the intensity of the Ruhemann's Purple in the developed blocks of amino acid.

For all phases of these trials the stepped amino acid concentration targets, once processed with ninhydrin, were scanned for brightness of each amino acid block. The scanning of all targets was carried out by Bounded Solutions Ltd. who supplied the authors with intensity data; this was then converted to give a linear 
density measurement for each block. In phases IV, V and VI these were scanned blind to knowledge of laboratory or process.

The y-axis in the presented plots (Figs 3-8) is uncalibrated due to changes in target design and scanner settings between experiments but is internally consistent for comparison of performance within each trial phase.

\section{Donor Fingermarks - Phases V and VI}

Using multiple male and female donors with a reasonable age range can provide representative fingermarks approximating to those encountered at crime scenes (29-31). The authors felt that 20 should provide a reasonable spread of amino acid distribution. Depletion series of fingermarks, where one finger is used to deposit several fingermarks one after the other with no significant pause between each deposition, provides a good range of quantities of deposit. Depending on technique, generally between four and ten depletions are adequate, and six was chosen for these trials.

Such donor fingermarks are best taken from a donor group with no special preparation, the only proviso being that the donor has not washed their hands for at least 30 minutes prior to deposition. Where hand creams or similar preparations have been used recently it is good practice to record this and for only a small proportion of such donor fingermarks to be accepted. The use of split marks, a number of donors and multiple levels of latent deposit, as achieved by depletion fingermarks, all contribute to the accuracy and objectivity of any evaluation and comparison.

An experiment based on a donor panel of 20 using six fingers (Fore, Middle and Ring of each hand) with six depletions was designed and an A4 target sheet was printed for each donor (Fig 2). Fingermarks were collected from the donors in accordance with the local ethical approval requirements. All samples were anonymised and only identifiable by an alphanumerical code to permit data analysis.

Donors in Phase V were 14 males aged 20 to 59 and 6 females aged 20 to 33 and in Phase VI 15 males aged 20 to 47 and 5 females aged 21 to 37.

\section{Ninhydrin Formulations and Treatment Protocols}

\section{CAST FORMULATION}

A ninhydrin stock solution (40) was prepared by mixing $25 \mathrm{~g}$ ninhydrin with $225 \mathrm{~mL}$ absolute ethanol, before adding $10 \mathrm{~mL}$ ethyl acetate and $25 \mathrm{~mL}$ acetic acid. To prepare the working solution, $52 \mathrm{~mL}$ ninhydrin stock solution were added to 1 L HFE7100 and stirred for 5 minutes with a magnetic stirrer and stirring bar. A small amount of the working solution was poured into a curved trough. Each sample strip was drawn through the solution using plastic tongs, ensuring that it was completely immersed. The samples were left to dry for 5-10 minutes in a fume cupboard and then placed in a humidity controlled oven (Gallenkamp Sanyo 
Fingerprint Oven) at $80^{\circ} \mathrm{C}$ and $65 \%$ relative humidity for 7 minutes. In Phase $\mathrm{V}$ ninhydrin concentrations for some samples were reduced to $50 \%$ and $25 \%$.

\section{BKA FORMULATION}

A ninhydrin stock solution was prepared (41) by adding $15 \mathrm{~g}$ of ninhydrin to $100 \mathrm{~mL}$ ethanol and stirring with a magnetic stirrer until all crystals had dissolved, approximately 20 minutes at room temperature. 480 $\mathrm{mL}$ petroleum ether bp 40-60 were added to $20 \mathrm{~mL}$ ninhydrin stock solution and the mixture stirred on a magnetic stirrer for 5 minutes to give the working solution.

A small amount of the working solution was poured into a curved trough and each sample strip was drawn through the solution using plastic tongs, ensuring that it was completely immersed. The samples were left to dry for 5-10 minutes in a fume cupboard. They were then placed in an environmental chamber with saturated ammonium nitrate solution and ambient temperature $\left(18.6-21.7^{\circ} \mathrm{C}\right.$ and $\left.55-74 \%\right)$ for 96 hours for Phase V. In Phase VI, after communication with the BKA, samples were placed in a Sanyo Versatile Environmental Test Chamber set at $20^{\circ} \mathrm{C}$ and $65 \%$ for 48 hours.

\section{Fingermark Assessment in Later Parts of Programme}

Numerous arbitrary scales for the assessment of developed fingermark quality have been used and referred to in the literature (30,31). A version of the Home Office scale (Table 1) was used by two authors for phases V and VI but only assessing a $3 \mathrm{~mm}$ strip either side of the cut for the split marks. To generate comparative data from this assessment the number of fingermarks scoring three or four were totaled for each process divided by the number of sample fingermarks treated with that process.

One author blind assessed fingermarks on three 0 to 10 scales for Intensity, Definition and Ridge Continuity for Phase V and Ridge Intensity alone, as this proved representative, for Phase VI. The latter assessment was again confined to the visible ridge detail adjacent to either side of the cut edge.

The three assessors worked independently, two were experienced in fingermark assessment with one experienced assessor working blind with regards to treatment protocols.

No one system is ideal for all types of trial and when relying on visual examination, even with experienced fingerprint experts, the assessments are inevitably strongly subjective. In the case of ninhydrin treatment the primary requirements may be intensity of development, definition and background reaction. This is where objective scanning of amino acid targets could be of value. Mitigation of the limitations of visual assessment of developed fingermark quality can be achieved by increasing the number of donor fingermarks, using several independent assessors and carrying out such assessment blind to knowledge of sample treatments. The use of split fingermarks also enables direct side-by-side comparisons to be made which should improve grading accuracy. 


\section{EXPERIMENTAL PROGRAMME}

\section{Phase I - Initial Multi-Laboratory Trial}

A test target was printed similar to Fig 1 and samples from the same batch circulated to a number of UK and European police laboratories. On return these were scanned and the densities of the 16 target blocks plotted for each. The anonymised laboratory processed samples are plotted as A to F in Fig 3. A wide variation is seen in the intensity of development of all 16 target block concentrations.

Some laboratories processed more than one sample. Clearly treatment protocols were in some way producing widely varying intensity of reaction in the test targets, but it was not known how relevant this was to real fingermarks.

\section{Phase II - Inkjet-printed target batch consistency evaluation}

Five sample targets were taken from throughout a single inkjet-print run. These were processed by an experienced fingerprint laboratory under closely controlled conditions using the UK standard CAST formulation ninhydrin procedure (40). The processed targets were then scanned and density plotted for the 16 target blocks on the five samples, and they showed some variation but generally good consistency (Fig 4).

\section{Phase III - Investigation of ninhydrin solution depletion}

A revised batch of test targets similar to Fig 1 was produced and used to investigate changes in performance of a CAST formulation ninhydrin solution. It has long been operational practice to use ninhydrin solution until either it starts to go cloudy, oily droplets appear on the surface or other contamination appears $(32,40)$. This experiment consisted of passing a test target through $100 \mathrm{~mL}$ of a fresh solution in a trough followed by ten A4 sheets of clean plain white paper then a second test target. Scanning of the developed test targets showed good consistency of development between the first and second test targets.

In a second experiment two A4 sheets of each of five common types of paper, magazine and wrapping paper were passed through between the first and second test target. The solution was then left for several minutes until it started to go cloudy and a third test target was passed through.

Processing and scanning of the developed test targets again showed good consistency of development between the first and second test targets but some drop of intensity, particularly for the higher concentration blocks, for the third when the solution had gone cloudy Fig 5. This experiment therefore seemed to indicate that the final cloudy state of the ninhydrin solution was having some effect on the developed intensity of the test targets. This accords with unquantified experience in common operational working practices.

\section{Phase IV - IFRG collaborative experiment}

At the IFRG 2015 meeting in India delegates were invited to participate anonymously in this programme. A 
number of police and research laboratories subsequently processed targets of the type shown in Fig 1 which were returned and scanned and the densities for the 16 amino acid blocks plotted, shown as Lab 1 to 6 in Fig 6 . For the sake of clarity some plots have not been included, particularly some laboratories returning multiple targets but those presented are representative of the observed spread.

Differences were again observed between the target block densities achieved by the various laboratories. The spread of densities was wider than any observed during quality control tests which are reported as Phase II. This seems to indicate that there were differences in the effect of the treatment protocols used in the various laboratories on the test targets. At this stage it was unclear whether this effect would be reflected in fingermark developed intensity. In particular, differences in performance in the region of the lower concentration blocks 14, 15 and 16 may result in weaker fingermarks not being detected.

\section{Phase V - Targets vs Real Fingermarks Trial - Four Formulations Two Treatment Protocols}

A key objective of this programme of work was to establish whether varying levels of development seen on test targets with various treatments were a true reflection of the likely intensity of fingermark development. Two of the formulations which gave relatively high test target densities were selected for this phase, the CAST and BKA formulations which differ substantially in their solution formulation and subsequent temperature and humidity treatment protocols. A dedicated trial was designed and carried out in a university laboratory in the summer of 2017 with a donor panel of 20 using test targets of the type shown in Fig 2.

Four formulations and two temperature humidity protocols were used:

CAST standard formulation and standard treatment protocol (CAST std);

CAST with 50\% ninhydrin concentration and standard treatment protocol;

CAST with 25\% ninhydrin concentration and standard treatment protocol;

BKA standard formulation and 96 hours at high humidity; it was later learnt that 48 hours was usually used operationally (BKA std).

The A4 sheets with six fingermark depletions from each of six fingers from one donor were split to enable each half fingermark to be processed using a different treatment and each strip had a set of blocks of amino acid. For each split fingermark one half was treated with the CAST standard formulation and the other half with one of the other three treatments (Fig 2). Fingermarks were stored for one week in a closed filing cabinet in an office environment prior to enhancement.

In the fingermark assessment (Fig 7) the CAST ninhydrin 100\% (standard CAST) and CAST ninhydrin 50\% gave similar evaluations. The y-axis is arbitrary as the results of the independent scorers and scanned density values have been scaled to incorporate into one plot and enable comparison of ranking. It had been expected that the standard formulation contained 'excess' ninhydrin, probably explaining the similar scores, although 
this may be of value when processing large volumes of material.

The CAST $25 \%$ ninhydrin concentration resulted in a lower evaluation by all assessors. The BKA treatment, although it was subsequently found that a longer than usual humidity treatment was being used, resulted in a slightly higher fingermark assessment than the standard CAST.

The two fingermark assessments and three target block densities gave a similar ranking for the treatments (Fig 7). It can be seen that the lowest concentration amino acid block measured, Block 16, gave best discrimination between processes and followed the fingermark rankings.

Approximately 16 to $30 \%$ of fingermarks in this trial, carried out in the summer of 2017, yielded fingermark scores approximating to 3 or 4 if assessment of the narrow strip adjacent to the split was representative of a whole fingermark.

\section{Phase VI - Targets vs Real Fingermarks - Investigation of Treatment Protocols}

In Phase V, the CAST and BKA formulations both gave good results but using different solvent systems and widely different temperature and time treatment protocols. Considering that other work $(15,16)$ established that the CAST formulation required the high temperature and high humidity protocol for optimum development it is interesting to note that for the BKA formulation using a different solvent, high humidity is also recommended but room temperature for good development.

A further experimental design was therefore drawn up to compare the two formulations each at both temperature, humidity and time protocols. At this stage it was advised that the BKA procedure was usually 48 hrs at RT and $65 \%$ RH so this was adopted.

The inkjet-printed target design for this phase was of the type shown in Fig 2. The donor panel was again 20 and fingermarks were taken during the winter of 2019 and were stored for one week in a filing cabinet in an office environment prior to enhancement.

There may be a small difference in the intensity of fingermarks and target development between the standard CAST and BKA formulations and treatments. However, changing over the temperature and humidity post treatments for the two formulations results in dramatically poorer performance with both formulations, for the split fingermarks and the amino acid targets.

Plotting scores of the two assessments and three of the target blocks gave a similar ranking for the treatments (Fig 8). The y-axis is arbitrary, as scores have been scaled to incorporate into one plot and enable comparison of ranking. Approximately 13 to 15\% of fingermarks in this trial, carried out in the winter of 2019, yielded fingermark scores approximating to 3 or 4 if assessment of the narrow strip adjacent to the split was representative of a whole fingermark. Many of the donors produced only very faint, or no, visible fingermarks with any technique. The data is therefore not as robust as in Phase $\mathrm{V}$ but a similar ranking is still observed. 


\section{The Use of Targets for Other Amino Acid Reagents}

This programme of work aimed to establish whether mixtures of amino acids printed on to paper would behave in a similar way to latent fingermarks when treated with enhancement reagents. There are many amino acid reagents which have been used, or proposed, for operational police use. Currently most authorities agree that ninhydrin and zinc formulated indanedione are the most sensitive and productive. Many police forces rely on ninhydrin for most general casework, reserving ninhydrin followed by indanedione/zinc for more serious cases.

The intensity of Ruhemann's Purple in a visible ninhydrin reaction is relatively easy to accurately measure with some form of photometer or scanner; calibration of the measurement device is also relatively easy and reproducible.

In principle, the basic methodology used here could be applied to evaluating indanedione/zinc treatment. To measure the performance of a fluorescent enhancement treatment many parameters have to be controlled, measured or standardised. Fluorescent reagents have absorption and emission spectra, which generally overlap. Selecting and controlling the excitation and emission wavelength ranges poses substantial problems in terms of light source stability, band pass filter specifications and photometer calibration. There are other factors including geometry of illumination and substrate fluorescence that can influence the fluorescent signal. In addition, the fluorescent product characteristics may depend on the amino acid distribution in the fingermark. None of these are probably insurmountable but it is logically sensible to compare the performance of the printed amino acid targets with real fingermarks first with ninhydrin as demonstrated here.

\section{Conclusion}

This study has shown that the inkjet-printing of simple mixtures of amino acids on to paper can provide test targets which effectively emulate latent fingermarks in reactions with ninhydrin. It has been shown that these test targets can be used for routine reagent quality control and process verification far more accurately and reliably than the use of small numbers of donor fingermarks. Multiple test targets can be produced reproducibly in batches and scanning provides an objective measure of intensity of development. This study demonstrates the future potential use of inkjet-printed test targets using solutions of fingermark constituents such as amino acids in fingermark enhancement quality assurance.

Phases I, III, IV, V and VI all show that variations between laboratory treatments cause measurable variations in the intensity of the ninhydrin enhancement measured by the optical densities of blocks of inkjet-printed representative mixtures of amino acid. 
Phase II demonstrated that it is possible to print batches of such inkjet-printed stepped amino acid concentration targets with good reproducibility.

Phases V and VI showed that the variations in target block developed intensity follow quite closely the observed variations in fingermark image intensity and quality in test fingermarks on one type of paper. It is highly likely that this variation is representative of the performance in developing operational crime scene fingermarks.

In phases V and VI two very effective techniques were compared and differences still detected, poorer treatment protocols are likely to give more discrimination.

It appears that worldwide there are probably substantial variations in the effectiveness of ninhydrin processing with potentially serious operational implications. Solutions of amino acid, representative in terms of both average distribution and amounts of those typically in latent fingermarks, when inkjet-printed as test targets for ninhydrin, appear to be an objective and representative way of establishing and monitoring reagent performance.

The standard, but very different, BKA and CAST formulations require very different heat treatments but both give good enhancement. It is not clear why varying the solvent has such a dramatic effect on the optimum heat and time protocols, and it seems that some aspects of the ninhydrin reaction with amino acids on paper are still not understood. A larger scale experiment would be needed to definitively compare the two processes.

If inkjet-printed targets are used for process optimisation, rather than monitoring, a wider range of paper types would need to be used. The authors are carrying out a small such study.

\section{References}

1. S. Oden, B. von Hofsten, Detection of Fingerprints by the Ninhydrin Reaction, Nature, (1954) March 6 , pp 449-450.

2. S. Oden, A process of Developing Fingerprints on paper and the like materials, Patent Specification (1957) 767, 341, January 30. London: The Patent Office.

3. D. A. Crown, The Development of Latent Fingerprints with Ninhydrin, J. Crim. Law, Criminol. \& Police Sci. (1969) vol. 60 (2), pp 258-264.

4. J. J. Lesk, (1972) Development of Latent Fingerprints by the Ninhydrin Method, Ident. July, pp 1315.

5. J. R. Morris, G.C. Goode, \& J. W. Godsell, Some new developments in the chemical development of latent fingerprints. Police Research Bulletin, (1973) vol 21, 31-36.

6. T. Kent, (ed) Manual of Fingerprint Development Techniques, 1st edition. ISBN 0862522307. (1986 
(revised 1987, 1992)) London: Home Office.

7. U. Ramminger, U. Nickel, B. Geide, Enhancement of an Insufficient Dye-Formation in the Ninhydrin Reaction by a Suitable Post Treatment Process, J. Forensic Sci. (2001) 46 (2), pp 288-293

8. S. J. Ruhemann. Triketohydrindene Hydrate, J. Chem. Soc. (1911) (Trans.), vol. 97, pp 2025-2031.

9. P. J, Lamothe, G. P. McCormick. Role of hydrindantin in the determination of amino acids using ninhydrin. Anal Chem. (1973) vol 45 (11): 1906-11. https://doi.org/10.1021/ac60333a021

10. D. J. McCaldin, (1960) The chemistry of ninhydrin, Chem. Rev. (1960) vol 60 (1) 39-51 https://doi.org/10.1021/cr60203a004

11. D. C. Wigfield, G. W. Buchanan, M. Croteau, On Ruhemann's purple. Can. J. Chem. (1980) vol 58 (3), pp 201-205.

12. M. M. Joullié, T. R. Thompson, \& N. H. Nemeroff, Ninhydrin and Ninhydrin Analogs. Syntheses and Applications. Tetrahedron, (1991) vol 47 (42), pp 8791-8830. https://doi.org/10.1016/S0040$\underline{4020(01) 80997-2}$

13. N. D. K. Petraco, G. Proni, J. Jackiw, A-M. Sapse, Amino Acid Alanine Reactivity with the Fingerprint Reagent Ninhydrin. A Detailed Ab Initio Computational Study, J. Forensic Sci., (2006), vol 52 (6), pp 1267-1275. https://doi.org/10.1111/j.1556-4029.2006.00271.x

14. D. F. Hewlett, V. G. Sears, Replacements for CFC113 in the Ninhydrin Process: Part 1, J. Forensic Ident. (1997) vol. 47 (3), pp 287-299.

15. D. F. Hewlett, V. G. Sears, S. Suzuki, Replacements for CFC113 in the Ninhydrin Process: Part 2, J. Forensic Ident. (1997) vol. 47 (3), pp 300-306.

16. D. F. Hewlett, V. G. Sears, An Operational Trial of Two Non-ozone Depleting Ninhydrin Formulations for Latent Fingerprint Detection, J. Forensic Ident. (1999) vol. 49 (4), pp 388-396.

17. A. V. Petruncio, A Comparative Study for the Evaluation of Two Solvents for Use in Ninhydrin Processing of Latent Print Evidence, J. Forensic Ident. (2000) vol. 50 (5), pp 462-469.

18. H. G. Linde, Latent Fingerprints by a Superior Ninhydrin Method, J. Forensic Sci., (1975) vol. 20, pp 581-584. https://doi.org/10.1520/JFS10307J

19. J. Nielson, Quality Control for Amino Acid Visualization Reagents, J. Forensic Sci., (1987) vol. 32 (2), pp. 370-376, https://doi.org/10.1520/JFS11140J.

20. R.D. Olsen, The chemical composition of palmar sweat, Fingerprint Ident. Mag. (1972) vol. 53 (10) $3-23$.

21. F. Cuthbertson 1972 AWRE-SSCD Memo 332 The Chemistry of Fingerprints (currently not publicly 
available)

22. G.M. Mong, C.E. Petersen, T.R.W. Clauss, Advanced fingerprint analysis project final report fingerprint constituents. Technical Report, 1999. Pacific Northwest National Laboratory, 1999

23. R. S. Croxton, Ph D Thesis Analysis of Latent Fingerprint Components by Gas Chromatography Mass Spectrometry University of Lincoln, 2008

24. R. S. Croxton, M. Baron, D. Butler, T. Kent, V. Sears, Variation in amino acid and lipid composition in latent fingerprints, Forensic Sci. Int., (2010) vol 199, pp 93-102.

https://doi.org/10.1016/i.forsciint.2010.03.019

25. A. Girod, R. Ramotowski, C.Weyermann, Composition of fingermark residue: a qualitative and quantitative review, Forensic Sci. Int. (2012) vol 223, pp 10-24.

https://doi.org/10.1016/j.forsciint.2012.05.018

26. T. Atherton, R. S. Croxton, M. Baron, J. Gonzalez-Rodriguez, L. Gámiz-Gracia, \& A. M. GarcíaCampaña, (2012). Analysis of amino acids in latent fingerprint residue by capillary electrophoresismass spectrometry, J. Sep. Sci., (2012) vol 35 (21), pp 2994-2999.

https://doi.org/10.1002/jssc. 201200398

27. M. de Puit, M. Ismail, \& X. Xu, LCMS analysis of fingerprints, the amino acid profile of 20 donors, J. Forensic Sci. (2014) vol 59(2), pp. 364-370. https://doi.org/10.1111/1556-4029.12327

28. W. van Helmond, C-J. Kuijpers, E. van Diejen, J. Spiering, B. Maagdelijn. \& M. de Puit, Amino acid profiling from fingerprints, a novel methodology using UPLC-MS. Anal. Methods, (2017) vol 9, 5697-5702. https://doi.org/10.1039/C7AY01603D

29. T. Kent, Standardising Protocols for Fingerprint Reagent Testing, J. Forensic Ident., (2010), vol. 60 (3), pp 371-379.

30. V. G Sears, S. M, Bleay, H. L Bandey, and V. J. Bowman, A methodology for finger mark research, Sci. Justice, (2012), vol. 52 (3), pp 145-60. https://doi.org/10.1016/j.scijus.2011.10.006

31. J. Almog, A. Cantu, C. Champod, T. Kent, \& C. Lennard, Guidelines for the assessment of fingermark detection techniques International Fingerprint Research Group (IFRG). J. Forensic Ident. (2014) vol. 64, pp 174-197.

32. S. Zadnik, W. van Bronswijk, A.A. Frick, P. Fritz, S.W. Lewis, Fingermark simulants and their inherent problems: A comparison with latent fingermark deposits. J. Forensic Ident., (2013) vol 63 (5), pp 593-608.

33. R. Steiner, S. Moret, and C. Roux, Evaluation of the use of chemical pads to mimic latent fingermarks for research purposes. Forensic Sci. Int., (2020) vol 314, 110411 
https://doi.org/10.1016/j.forsciint.2020.110411

34. L. Schwarz, An Amino Acid Model for Latent Fingerprints on Porous Surfaces, J. Forensic Sci., (2009) vol 54 (6) pp. 1323-1326 https://doi.org/10.1111/j.1556-4029.2009.01168.x

35. L. Schwarz, M. L. Hermanowski, Luftfeuchtigkeit als notwendige Bedingung für die daktyloskopische Spurensicherung mit Ninhydrin - Ein praxisorientierter und kostengünstiger Lösungsansatz mit Kaliumcitrat“, Archiv f. Kriminologie, (2010) vol 225, pp 39-45.

36. L. Jacobs - Thesis - Teststrookjes voor aminozuurreagentia. Artificial fingerprints as quality control for amino acid reagents used for fingerprint detection. Private Communication.

37. Artificial fingerprints as quality control for amino acid reagents used for fingerprint detection, Report by Bert Lesger, Researcher Lauren Jacobs Police Academy of the Netherlands

38. S. Hong, I. Hong, A. Han, J. Y. Seo, J. Namgung, A new method of artificial latent fingerprint creation using artificial sweat and inkjet printer, Forensic Sci. Int. (2015) vol. 257, pp 403-408. https://doi.org/10.1016/j.forsciint.2015.10.005

39. R. Janssen-Bouwmeester, C. Bremmer, L. Koomen, S. Siem-Gorré, M. de Puit, Positive control tests for fingermark development, Forensic Sci. Int. (2020) vol 310, 110259, https://doi.org/10.1016/j.forsciint.2020.110259

40. H. Bandey, (ed) (2014) Fingermark Visualisation Manual, ISBN 978-1- 78246-234-7 London: Home Office

41. I. Becker, L. Schwarz, I. Klenke, M.-L. Heinrich, M. Bust, "Process Instruction » Ninhydrin « 3.2en “, 2018, Bundeskriminalamt, Wiesbaden 
Table 1 - Home Office scale for assessment of fingermark enhancement quality (30)

Fig 1 - One of several early designs of test target (Bounded Solutions Ltd)

Fig 2 - Test sheet with target blocks of amino acid and spaces for vertical depleted fingermark series designed to be cut into seven pieces before processing (Bounded Solutions Ltd.)

Fig 3 - Initial trials with UK and European police laboratories (anonymised, A to F) using a target such as that in Fig 1

Fig 4 - Five randomly taken targets from a batch processed under the same conditions by an experienced fingerprint laboratory using the UK standard CAST formulation

Fig 5 - Ninhydrin solution depletion experiment comparing test targets treated before (Start) and after 10 sheets of paper of mixed types (Finish), and once the solution had turned cloudy using a target such as that in Fig 1

Fig 6 - IFRG Trial results (anonymised, Labs 1-6) using a target such as that in Fig 1

Fig 7 - Comparison between four ninhydrin formulations using a target such as that in Fig 2 and donor latent fingermark depletions

Fig 8 -Comparison between two ninhydrin formulations and two heating protocols using a target such as that in Fig 2 and donor latent fingermark depletions 


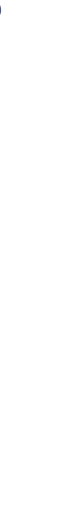
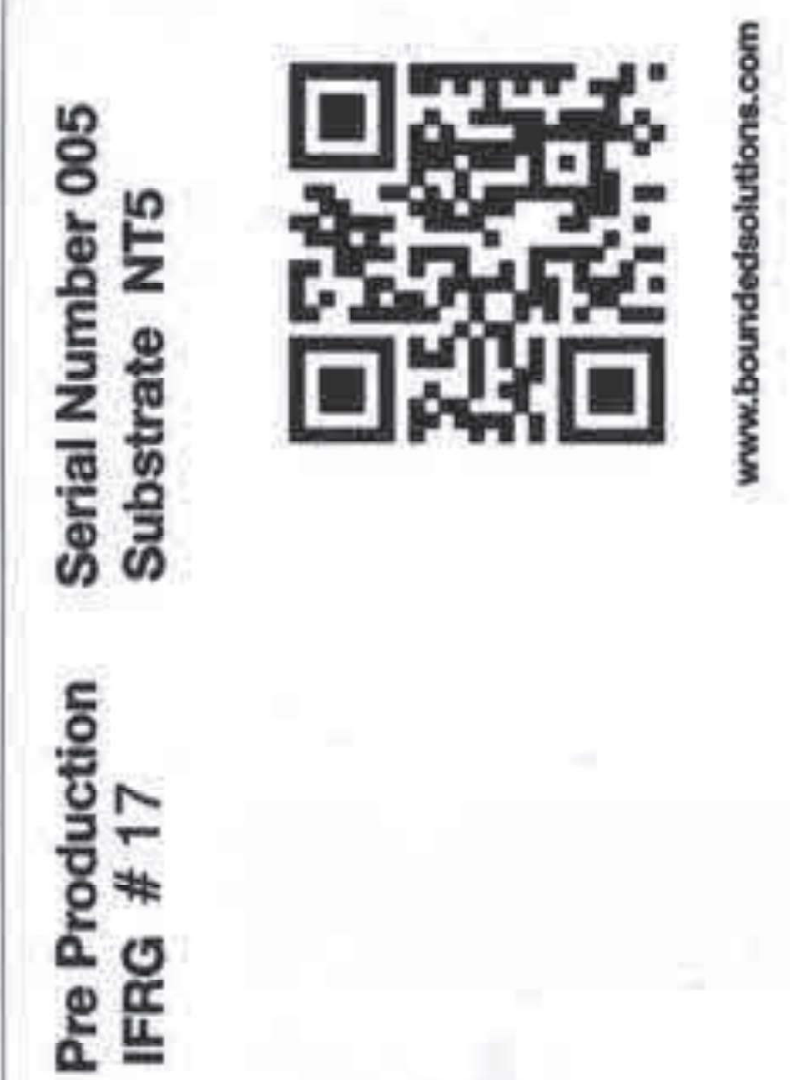

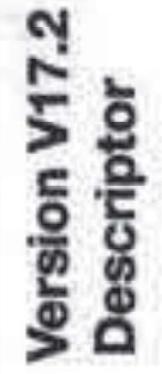
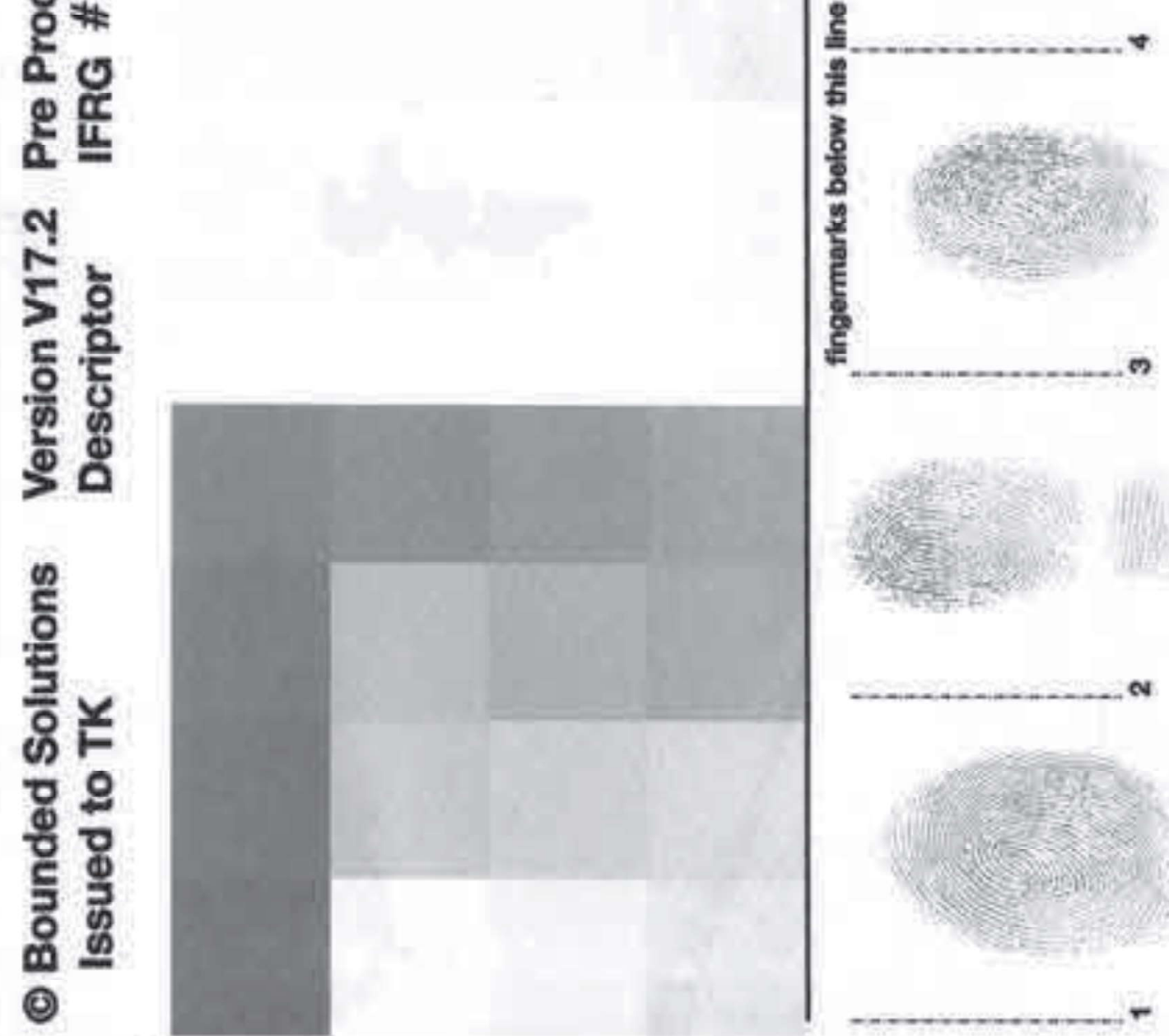


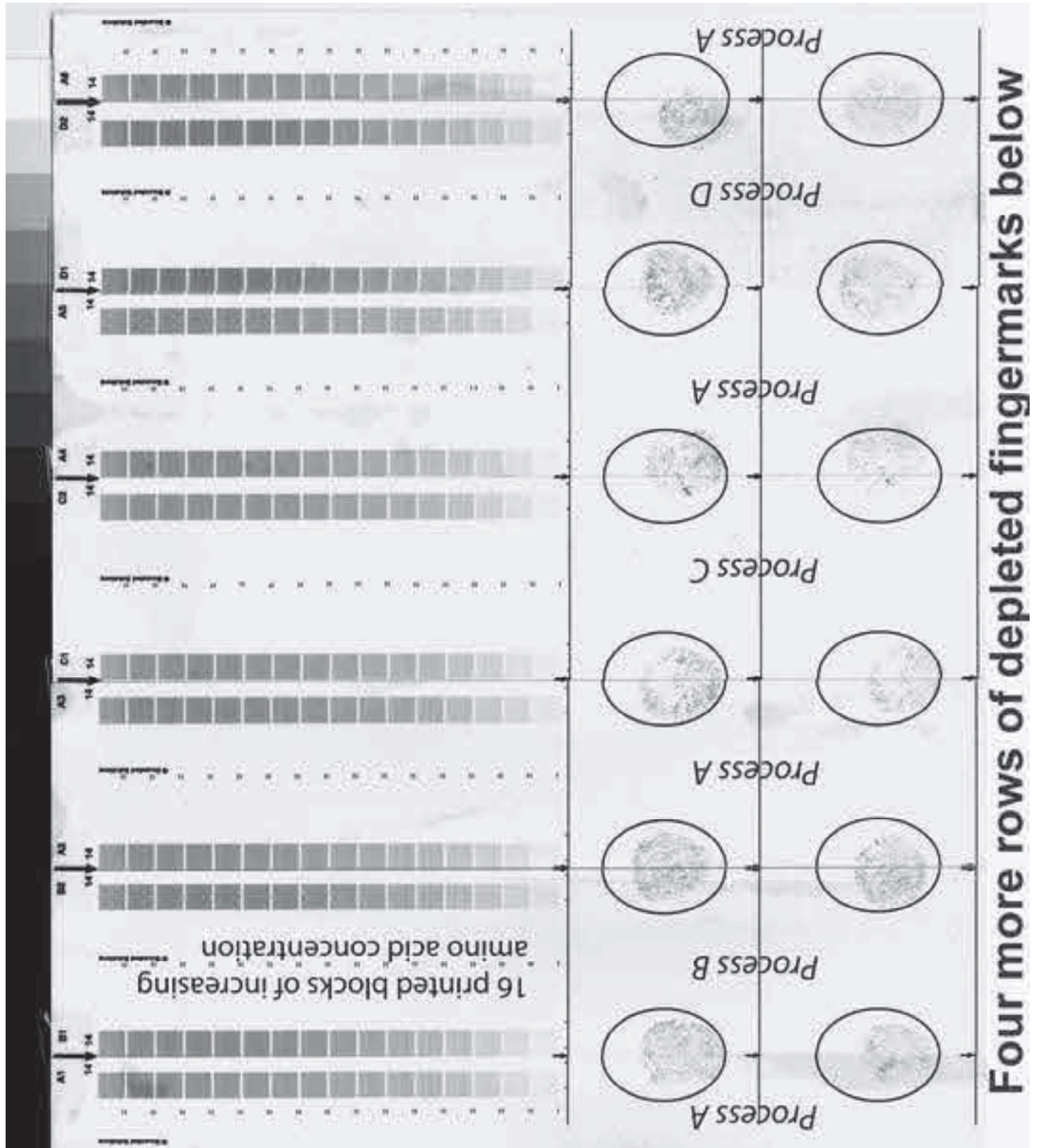




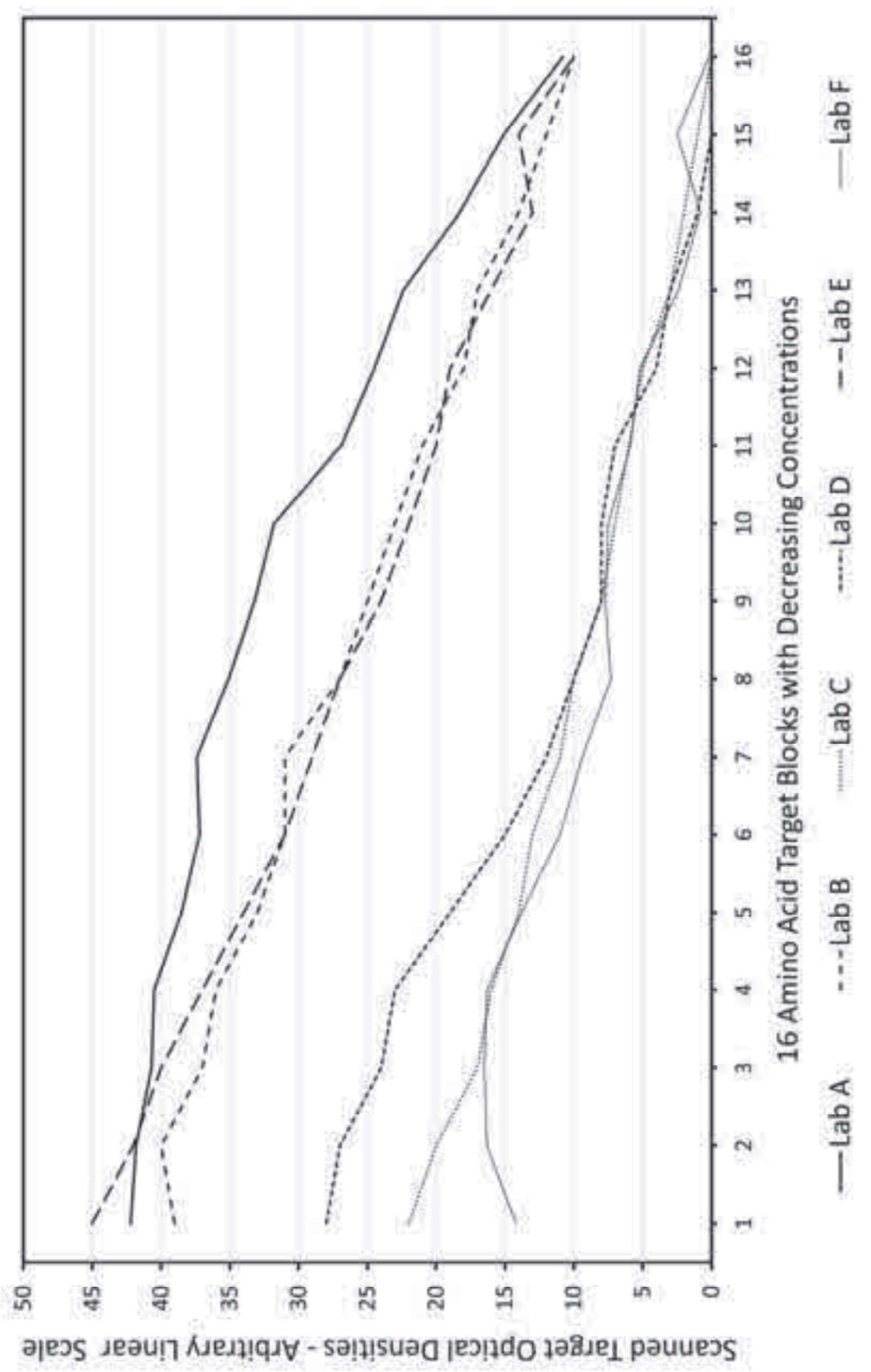

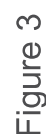




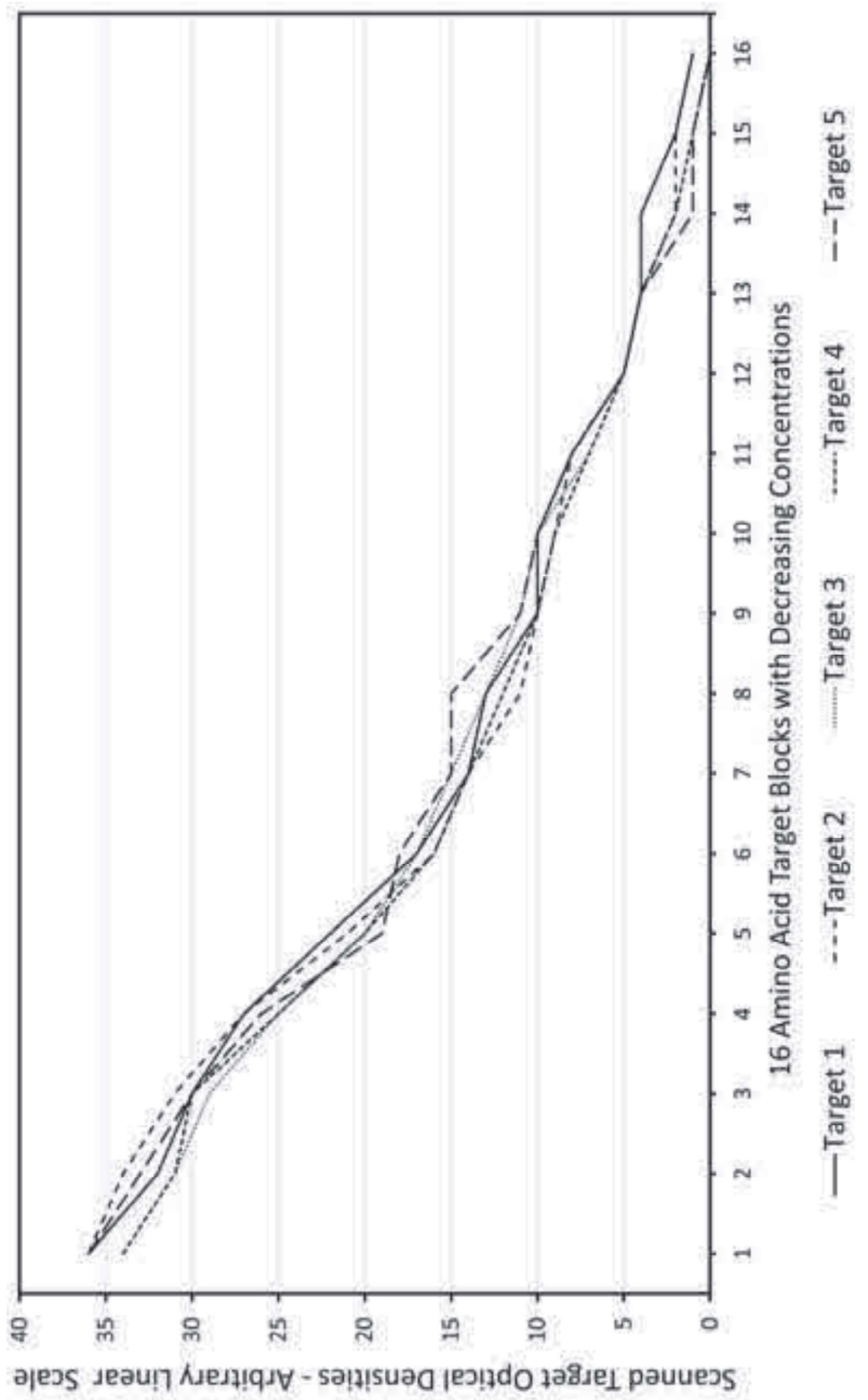

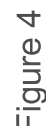




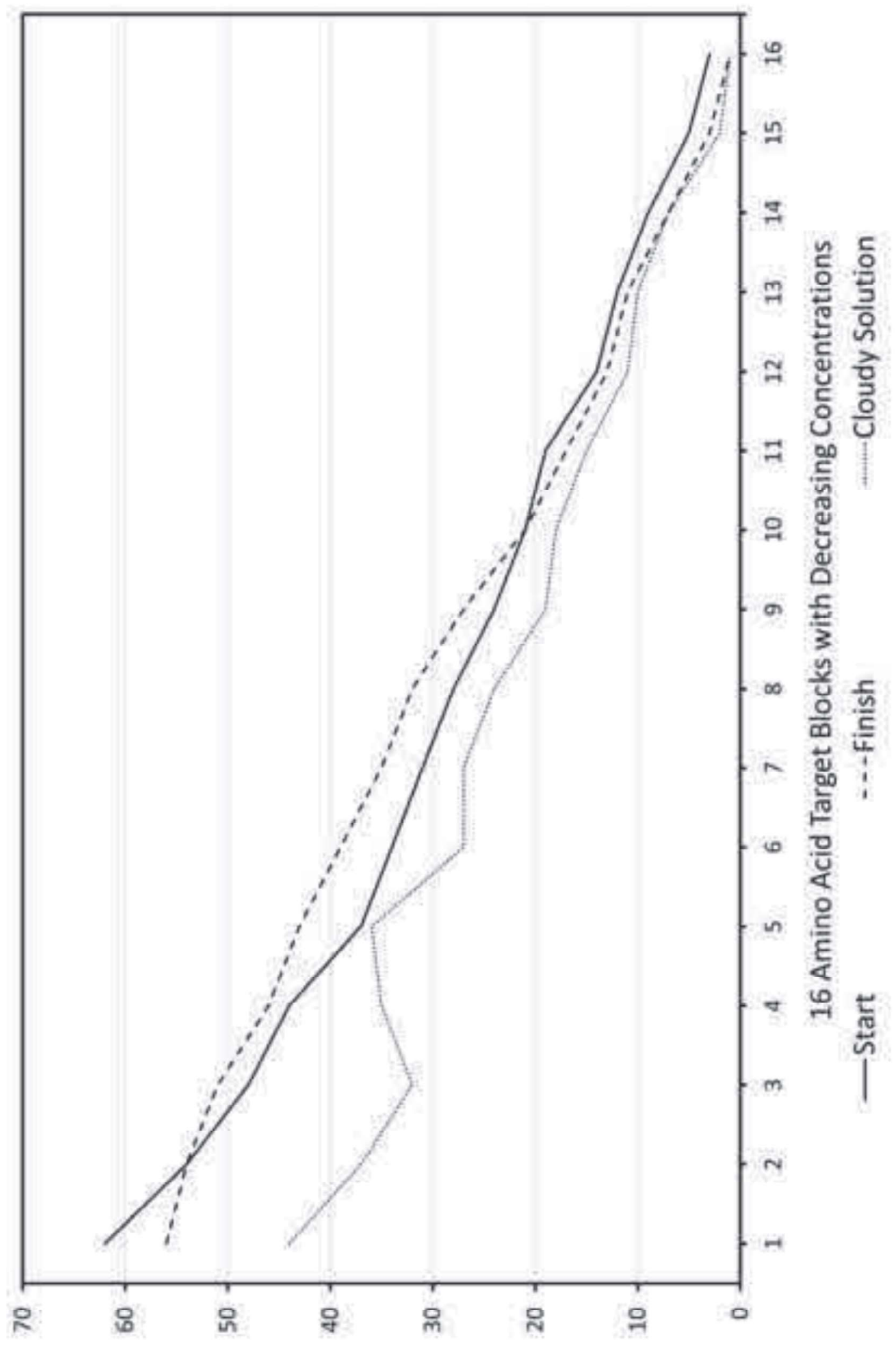

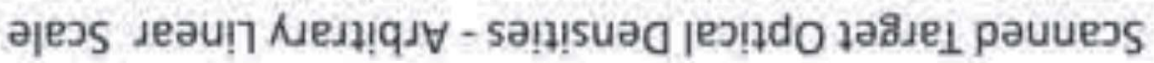

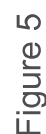




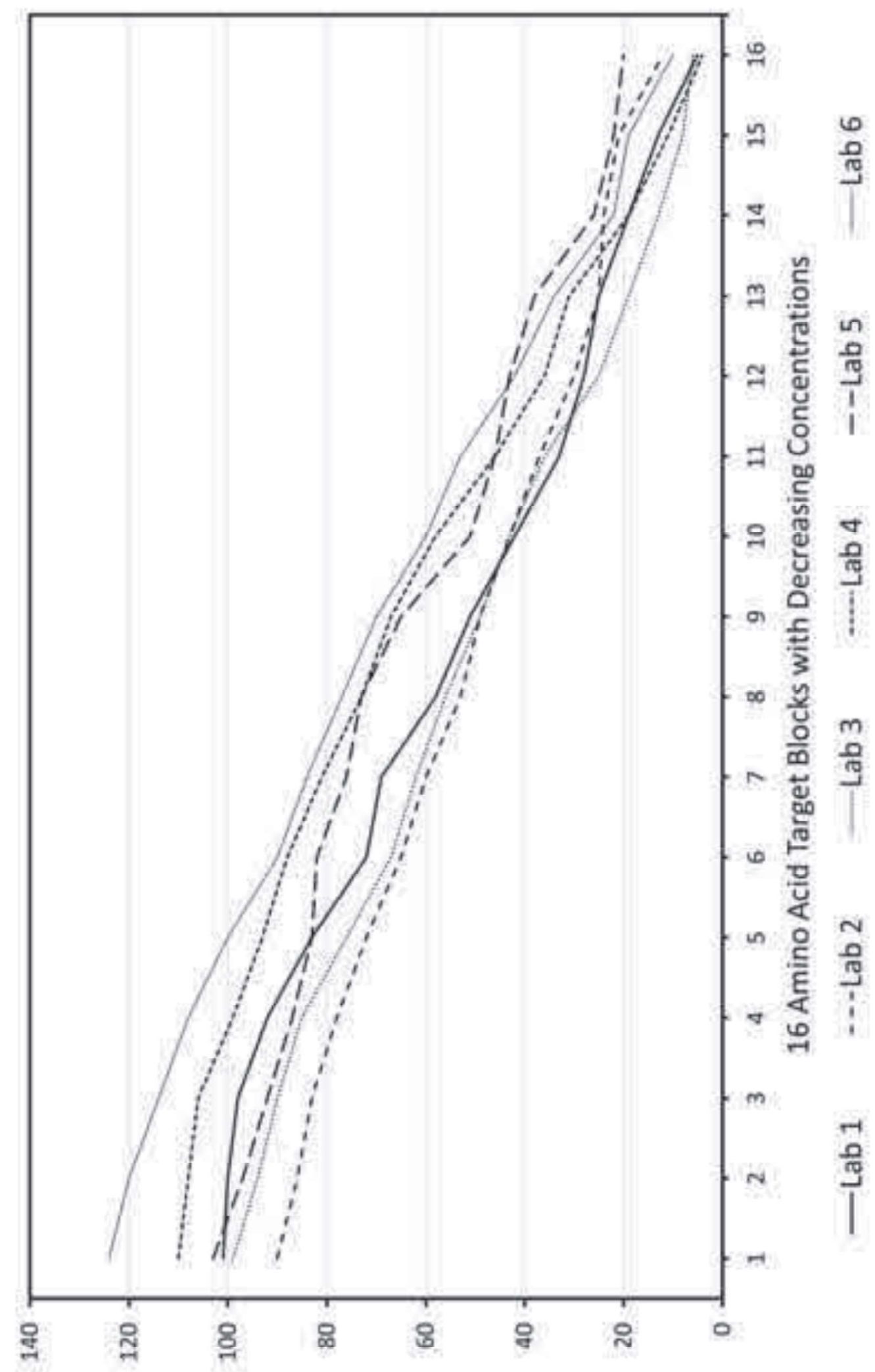

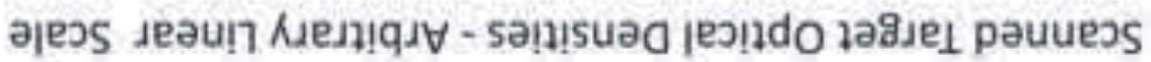




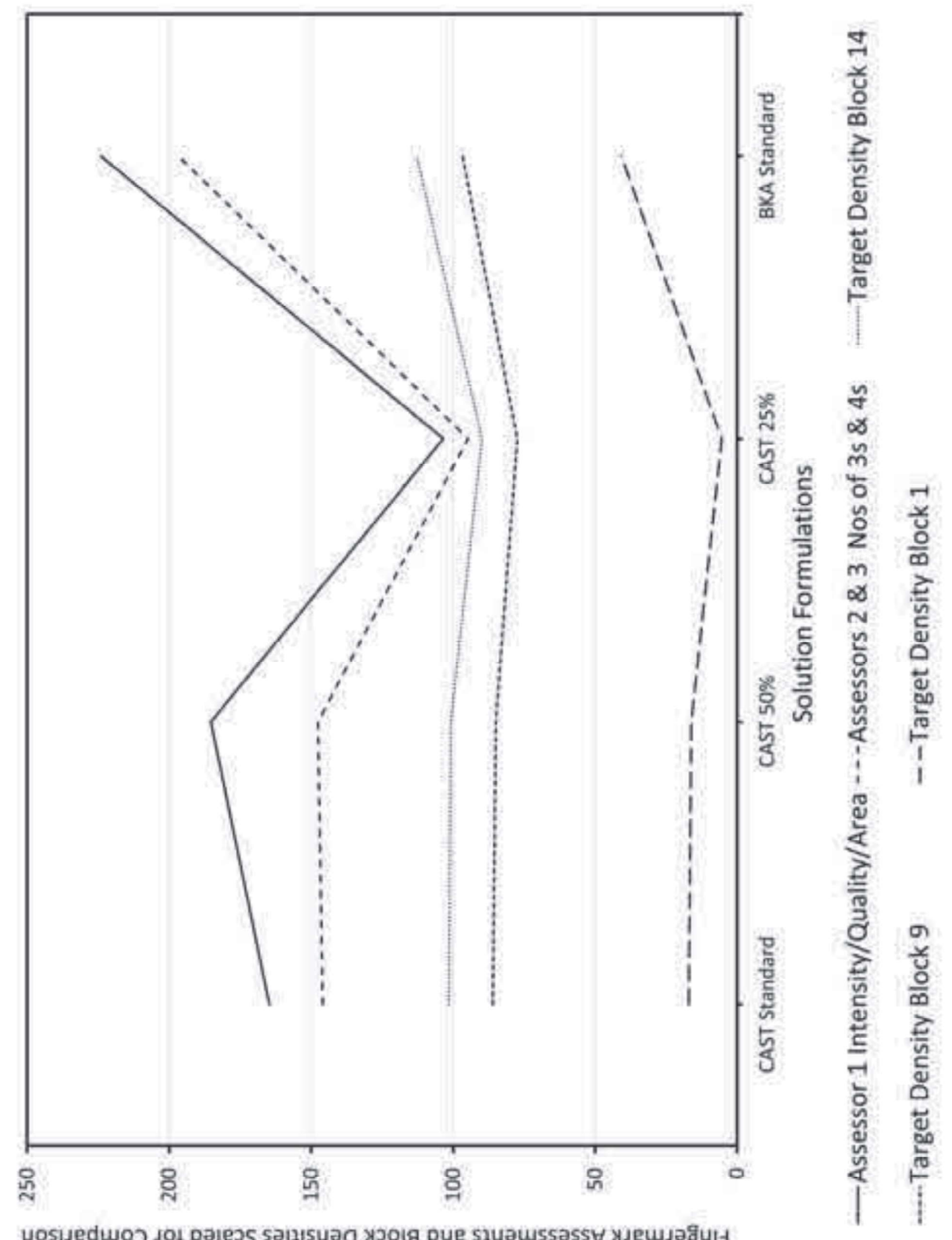

uosjsedwoว jof pajeวs sa!łısua 


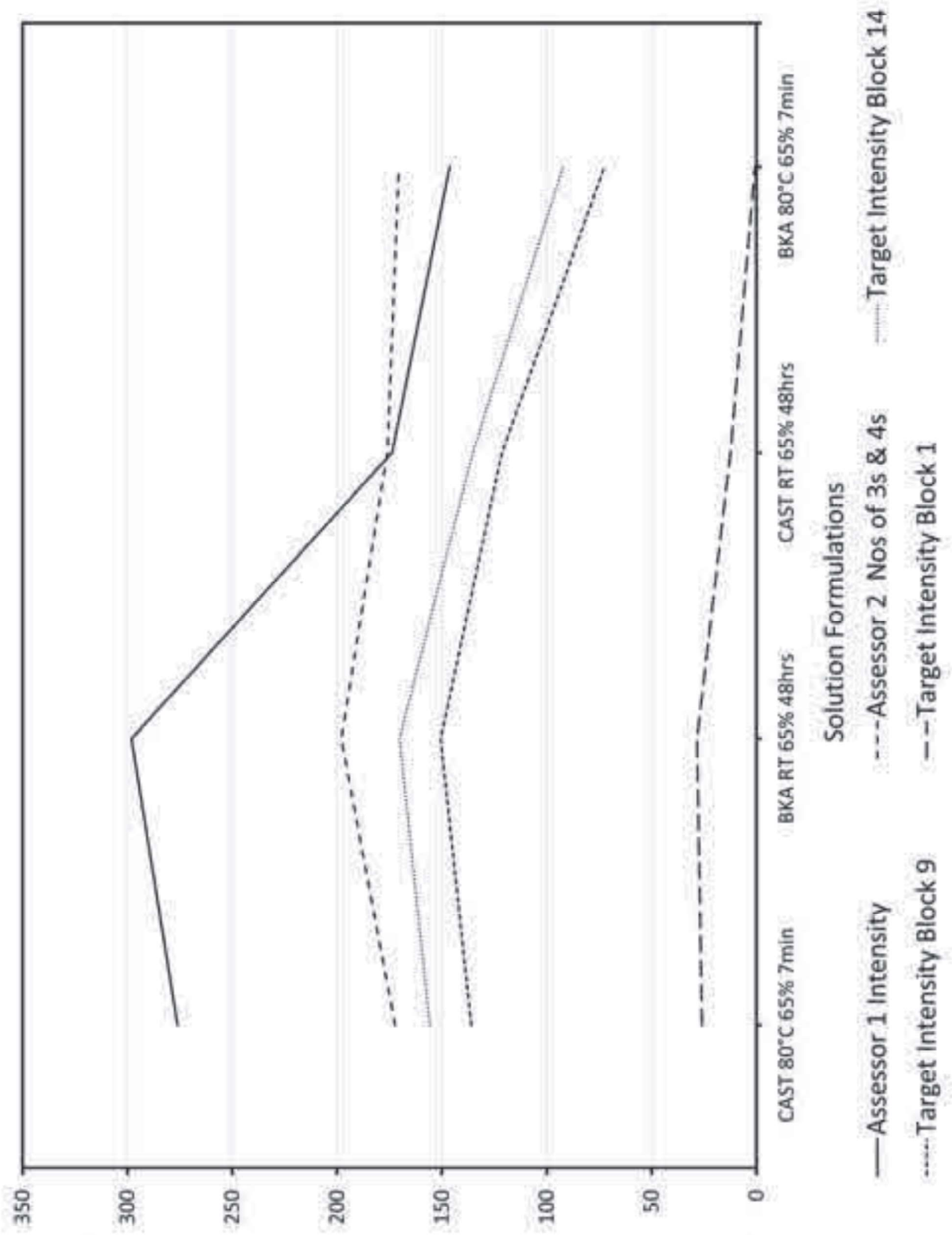

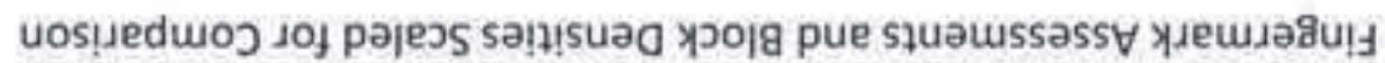




\begin{tabular}{ll}
\hline Grade & Description \\
\hline 0 & No development \\
1 & No continuous ridges; all discontinuous or dotty \\
2 & $\begin{array}{l}\text { One third of the mark comprised of continuous ridges; } \\
\text { remainder either shows no development or dotty }\end{array}$ \\
3 & $\begin{array}{l}\text { Two thirds of the mark comprised of continuous ridges; } \\
\text { remainder either shows no development or dotty }\end{array}$ \\
4 & $\begin{array}{l}\text { Full development; whole mark comprised of continuous } \\
\text { ridges }\end{array}$ \\
\hline
\end{tabular}

Table 1 - Home Office scale for assessment of fingermark enhancement quality (30) 